\title{
SARCOMA FUSOCELULAR COM METÁSTASE PULMONAR E ESPLÊNICA EM CANINO - RELATO DE CASO
}

(Fusocelular sarcoma with pulmonary and splenic metastasis in canine - Case Report)

\author{
${ }^{1}$ Lizandra de Fátima Brandão Torquato, ${ }^{1}$ Felipe Noleto de Paiva, ${ }^{1}$ Juliana Pereira do Nascimento, ${ }^{1}$ Danielle Carlos Silva, \\ ${ }^{2}$ Laércio Correia Fernandes Junior, ${ }^{1}$ Thiago Souza Costa, ${ }^{1}$ Julio Israel Fernandes
}

${ }^{1}$ Universidade Federal Rural do Rio de Janeiro, Rio de Janeiro, Brasil. ${ }^{2}$ Médico Veterinário Autônomo, Rio de Janeiro, Brasil.

*Correspondência: lizandrabrandao@hotmail.com

RESUMO: Os sarcomas de tecidos moles (STM) são neoplasias mesenquimais malignas, que acometem principalmente a pele e o subcutâneo, respondendo por 8 a 15\% dos tumores cutâneos caninos (Liptak; Christensen, 2020). O grupo é composto por uma série de neoplasias mesenquimais que possuem comportamento biológico, macroscopia e microscopia semelhantes entre si, e a ressecção cirúrgica é a terapia de eleição devido a sua agressividade local e baixa taxa de metástases (Liptak; Christensen, 2020). O presente trabalho relata um caso de um canino, fêmea, sem raça definida, de 11 anos de idade, atendido no Hospital Veterinário da Universidade Federal Rural do Rio de Janeiro, apresentando um tumor ulcerado em região perianal, com evolução rápida e crescimento progressivo. Durante 0 atendimento, 0 animal manifestava prostração, hiporexia, normodipsia, normoúria, normoquesia, e apresentava massa em região perianal direita, de consistência firme, aderida e ulcerada, medindo aproximadamente $9,0 \mathrm{~cm}$ em sua maior dimensão. Foi realizado exame citopatológico com a amostra coletada através de técnica aspirativa, com microscopia sugestiva de sarcoma de tecidos moles. Foram solicitados exames de radiografia torácica, ultrassonografia abdominal e hemograma para estadiamento clínico e avaliação da condição geral do animal. Durante radiografia foi evidenciada massa em região de mediastino aproximadamente $6 \mathrm{~cm}$. Foi realizada coleta de amostra para exame citopatológico guiada por ultrassonografia com diagnóstico sugestivo de sarcoma de tecidos moles. Os tutores optaram pela eutanásia do animal. Foi realizado exame de necropsia evidenciando massa de 7,0 × 6,0 × 4,0 cm em lobo pulmonar cranial esquerdo, múltiplos nódulos esplênicos variando entre $2,0 \times 2,0 \mathrm{~cm}$ a $4,0 \times 3,0 \mathrm{~cm}$, além da massa de 9,0 × 8,0 × 5,0 cm em região perianal. O diagnóstico histopatológico foi de sarcoma fusocelular, com metástases em pulmão e baço, sugerindo diagnóstico diferencial de fibrossarcoma. Os sarcomas de tecidos moles se manifestam majoritariamente como massas de tamanhos variados, crescimento lento, localizadas principalmente em tronco e membros (Dennis et al., 2011), contrariando a descrição do relato, em que o crescimento foi acelerado e em região atípica. As metástases são incomuns, ocorrendo em até $20 \%$ dos casos, principalmente para pulmões (Liptak; Christensen, 2020; Dennis et al., 2011), conforme caso apresentado, porém com metástase incomum em baço. O diagnóstico histopatológico pode ser dificultado em casos de baixa diferenciação, com difícil distinção da origem neoplásica, podendo ser necessário exame de imunoistoquímica (Liptak; Christensen, 2020). No relato o diagnóstico histopatológico foi de sarcoma fusocelular, sugestivo de fibrossarcoma. É importante considerar a possibilidade de disseminação mesmo em tumores que possuem baixos índices metastáticos, obtendo um estadiamento clínico fidedigno, de forma a estabelecer a melhor conduta terapêutica para o paciente.

Palavras-chave: baço; cão; neoplasia, pulmão, sarcoma

\section{Referências}

DENNIS, M. M.; MCSPORRAN, K. D.; BACON, N. J.; SCHULMAN, F. Y.; FOSTER, R. A.; POWERS, B. E. Prognostic factors for cutaneous and subcutaneous soft tissue sarcomas in dogs. Veterinary Pathology, v. 48, n. 1, p. 73-84, 2011.

LIPTAK, J. M.; CHRISTENSEN, N. I. Soft tissue sarcomas. In: WITHROW, S. J.; MACEWEN, E. G. (Ed.). Small animal clinical oncology. 4th. Ed. Philadelphia: WB Saunders, 2020. P. 404-431. 